\title{
A Double-Blinded Prospective Randomised Controlled Trial to Assess the Efficacy of Glubran-2 in Reducing Seroma Formation after a Mastectomy with or without Axillary Dissection
}

\author{
Zackariah Clement*, Peter Shin, Clive Hoffmann, Michael Eaton, William McLeay \\ Breast and Endocrine Surgery Unit, Flinders Medical Centre, Adelaide, Australia \\ Email: *zackariahc@yahoo.com
}

How to cite this paper: Clement, Z., Shin, P., Hoffmann, C., Eaton, M. and McLeay, W. (2017) A Double-Blinded Prospective Randomised Controlled Trial to Assess the Efficacy of Glubran-2 in Reducing Seroma Formation after a Mastectomy with or without Axillary Dissection. Advances in Breast Cancer Research, 6, 117-128. https://doi.org/10.4236/abcr.2017.64011

Received: August 28, 2017

Accepted: September 27, 2017

Published: September 30, 2017

Copyright (๑) 2017 by authors and Scientific Research Publishing Inc. This work is licensed under the Creative Commons Attribution International License (CC BY 4.0).

http://creativecommons.org/licenses/by/4.0/

\begin{abstract}
Background and Purpose: Seroma formation is a common complication following a mastectomy and axillary surgery. Decreasing the dead space is believed to decrease seroma formation. The aim of this study is to compare the incidence of seroma formation with the use of Glubran-2 versus normal saline during the wound closure in participants undergoing mastectomy with or without axillary dissection. Methods: This multicentre, prospective, double-blinded, randomised controlled trial, enrolled women 18 years of age or older with breast cancer, who were underwent total or partial mastectomy, with or without axillary dissection. Participants were randomised to Glubran-2 or Saline arm. The primary outcome was the volume and duration of wound seroma. Secondary outcome was post-operative wound infection. Results: A total of 76 women were randomised and there was no loss to follow-up or mortality. The total seroma volume was higher in the Glubran-2 arm. The duration of seroma was higher in the mastectomy and axillary dissection group in the Glubran-2 arm $(P=0.69)$. Elderly and participants with higher BMI had a higher volume of seroma. Post-operative infection rate was higher in the Glubran-2 arm ( $13.2 \%$ vs. $5.6 \% ; P=0.26)$. There was no statistically significant difference between the groups. Conclusion: Our study did not show any benefit with the use of Glubran-2 in mastectomy and axillary surgery in reducing the risk of seroma formation. In elderly and obese participants the use of Glubran-2 showed an increase in seroma formation and post-operative wound infection.
\end{abstract}




\section{Keywords}

Breast Cancer, Mastectomy, Axillary Dissection, Seroma, Glubran, Cyanoacrylate Glue

\section{Introduction}

Seroma formation is a common complication following a mastectomy and axillary dissection with an incidence reported between 5\% and 90\% [1]-[7]. Despite most seroma resolve within a few weeks, it often causes patient discomfort and other unnecessary complications such as infection and delayed wound healing. These complications can further delay commencement of adjuvant treatment and can also affect the overall patient recovery [1] [3] [5] [6] [7].

The risk factors for seroma formation include obesity, age, hypertension, breast volume, and use of electro-cautery [2] [8]. Some studies have reported that decreasing the dead space after surgery reduces seroma formation [6] [9] [10]. Several techniques have been trialled including drains, quilting sutures, fibrin glue, tetracycline sclerosing agents, methylprednisolone, and somatostatin analogues to reduce the dead space, volume and duration of seroma [2] [6] [7] [9]-[18]. Although some authors have reported that reducing the dead space minimises volume and duration of seroma, to date there is no general consensus in a single technique to reduce the risk of seroma formation [9] [10] [11].

More recently Glubran-2, which is a synthetic biodegradable cyanoacrylate based glue has been used in a wide number of surgical procedures. Glubran-2 polymerises rapidly on contact and firmly adheres to the tissues. It is reported to have good haemostatic and adhesive properties [18]-[24]. This adhesive property can obliterate the dead space after mastectomy and axillary dissection.

This prospective double-blinded randomised controlled trial compares the incidence of seroma formation with the use of Glubran-2 versus normal saline during the wound closure in participants undergoing total or partial mastectomy with or without axillary dissection.

\section{Methods}

\subsection{Study Design}

We conducted a multicentre prospective double-blinded randomised controlled trial involving 76 women. The inclusion criteria were that participants are 18 years of age or older, who had breast cancer of stage 0 to III, and in whom the diagnosis had been confirmed using biopsy (Fine needle or Core-needle biopsy).

The study was conducted across three hospitals in Adelaide, Australia. $\mathrm{Hu}$ man Research Ethics Committee at the three participating hospitals granted ethics approval. Glubran-2 and saline spray was supplied by Matrix Surgical Australia. 
Exclusion criteria for the study was neoadjuvant therapy, previous ipsilateral breast cancer, and on immunosuppressive therapy. Post-surgery participants were excluded if they developed post-operative haematoma requiring return to operating theatre for evacuation. Four experienced breast surgeons performed all the procedures.

\subsection{Recruitment}

The participants were enrolled in the study between the periods of $1^{\text {st }}$ August 2015 till $31^{\text {st }}$ October 2016. The surgeons identified potential participants at the time they were diagnosed at one of the three participating hospitals. Out of 104 patients who were assessed 76 met the inclusion criteria (Flow Diagram). Participants who met the inclusion criteria received a study and participant information sheet. After the selection criteria were satisfied, the consultant surgeon obtained a written informed consent and baseline data.

\subsection{Randomisation}

Eligible participants were enrolled in the study, with stratification into either Glubran-2 or Saline arms. Randomisation was performed using permuted block randomisation. In each stratum, participants were randomly assigned in a 1:1 ratio to having either Glubran-2 spray (Product A) or saline spray (Product B).

Using permuted block randomisation the participants were randomised into the following three groups: mastectomy without axillary dissection, mastectomy with axillary dissection, and partial mastectomy with axillary dissection. To avoid selection bias, allocation concealment was performed using sequential numbering. The data manager performed the block randomisation and allocation sequence. SPSS software version-24 was used for randomisation and statistical analysis.

\subsection{Blinding}

Both the investigators and participants were blinded to the content of the spray vials (Glubran-2 and Saline), which were identical in appearance. Prior to wound closure and based on the randomisation the surgical scrub nurse provided the surgeon the product. The participant's number was stored against the product used (Glubran-2 or saline).

\subsection{Surgical Technique}

Four experienced breast surgeons performed all the procedures. Participants underwent total mastectomy, partial mastectomy and axillary dissection using the standard operative techniques. According to the manufacturer's recommendation, after mastectomy, $1 \mathrm{ml}$ vial containing either Glubran-2 or saline was sprayed to the chest wall. After 10 seconds the skin flap was laid down on the chest wall with compression applied for 90 seconds. This procedure was repeated for the lower flap. In participants who underwent axillary dissection, $1 \mathrm{ml}$ 
of either Glubran-2 or saline was sprayed over the axillary fossa. One suction drain was placed in all participants who underwent total mastectomy and axillary dissection. After spraying the product the surgeon waited for 30 seconds before placing the drain in order to avoid adherence of the drain to the tissue. The drain was routinely removed on the second post-operative day and the participants were discharged home.

\subsection{Study Outcomes}

\subsubsection{Primary Outcomes}

The primary outcome was the volume and duration of wound seroma requiring aspiration. A seroma in this study is defined as a postoperative fluid collection on clinical examination. The aspiration frequency, volume and duration of seroma were collected in the participant's medical records by the surgeon and the breast care nurse.

\subsubsection{Secondary Outcome}

Post-operative wound infection.

\subsection{Follow-Up}

All participants were followed-up until the seroma resolved. Any loss to follow-up was recorded for statistical analysis.

\subsection{Data Management}

Data was recorded on a case report form (CRF). All participants were de-identified using a coded patient number in their CRF. Preoperatively all records that contain participants names or other identifying information were stored separately from the study records. The intervention arm was revealed to the clinicians post-surgery during the participant follow-up.

\subsection{Statistical Analysis}

Statistical analysis was performed using chi square tests for categorical variables and Mann-Whitney $\mathrm{U}$ tests for continuous variables. $P<0.05$ was considered evidence of statistical significance. A sample size of 102 participants was estimated to demonstrate a statistically significant difference with a power of $90 \%$. SPSS software version-24 was used for all statistical analysis.

\section{Results}

A total of 74 participants were recruited in this trial. After randomisation 38 and 36 participants were allocated to Glubran-2 and Saline arm respectively. There was no loss to follow-up or mortality (Figure 1). The enrolled participant's age and BMI were equally distributed amongst the three groups. The median age was 62.5 and 65 in the Glubran-2 and Saline arms respectively. The mean BMI was 27.8 in the Glubran-2 group and 28 in the Saline group (Table 1). 


\section{Enrollment}

$$
\text { Assessed for eligibility }(n=104)
$$

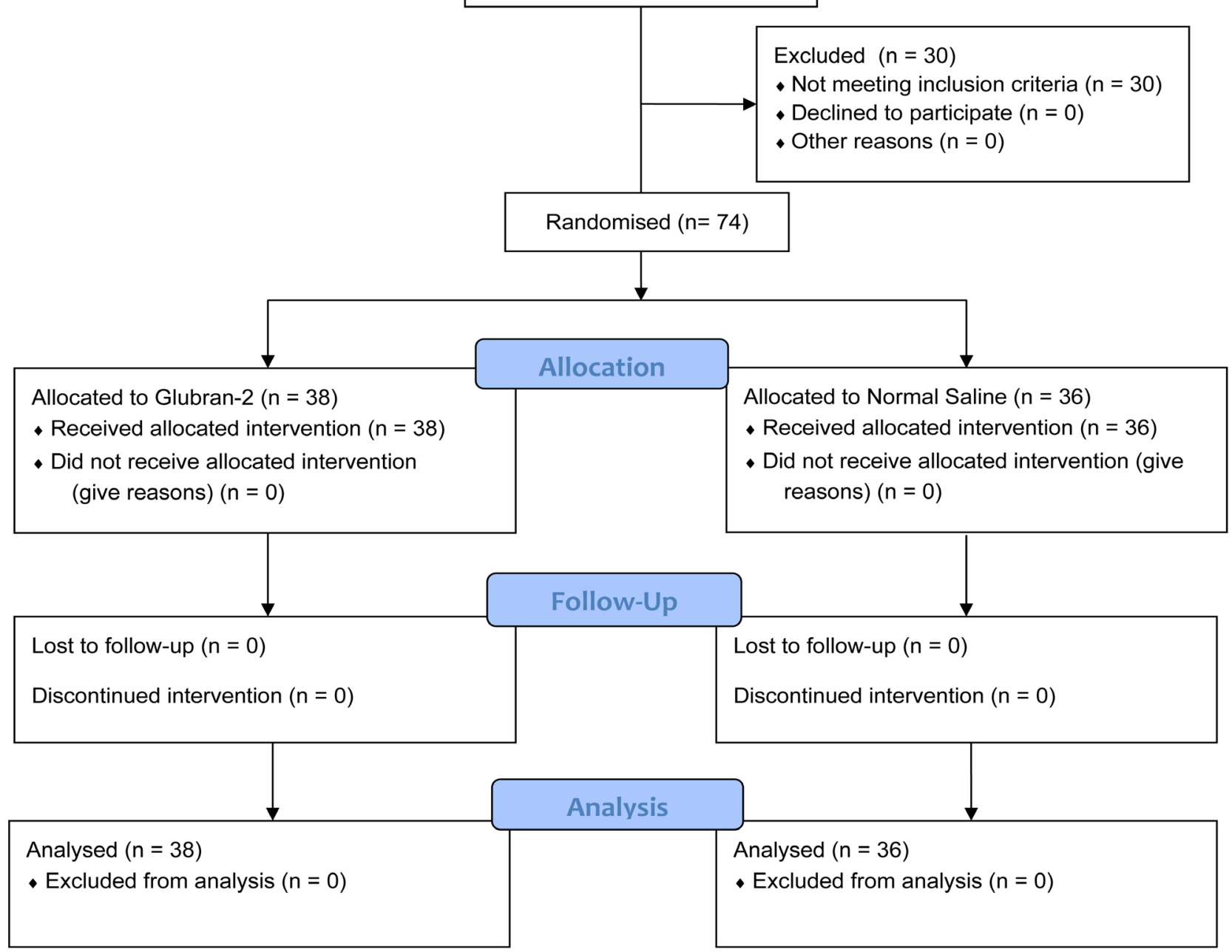

Figure 1. The randomised controlled trial.

Table 1. Patient baseline characteristics.

\begin{tabular}{|c|c|c|c|c|}
\hline & Characteristics & Glubran-2 $(n=38)$ & Saline $(n=36)$ & $P$-value \\
\hline & Age-year (Median) & $62.5(38)$ & $65.0(36)$ & 0.493 \\
\hline \multicolumn{5}{|c|}{ Median age in each group (n) } \\
\hline- & $<50$ years & $48.0(6)$ & $44.5(10)$ & 0.608 \\
\hline- & $50-60$ years & $51.5(8)$ & $58.0(3)$ & 0.061 \\
\hline- & $60-70$ years & $63.0(11)$ & $65.0(12)$ & 0.100 \\
\hline- & $>70$ years & $75.0(13)$ & $77.0(11)$ & 0.414 \\
\hline \multicolumn{3}{|c|}{ Treatment Group } & & \multirow[t]{4}{*}{0.961} \\
\hline- & Total Mastectomy & $16(42.1 \%)$ & $14(38.9 \%)$ & \\
\hline- & Total Mastectomy and Axilla Dissection & $16(42.1 \%)$ & $16(44.4 \%)$ & \\
\hline- & Partial Mastectomy and Axilla Dissection & $6(15.8 \%)$ & $6(16.7 \%)$ & \\
\hline & BMI (Mean) & $27.8[25.8-29.8](32)$ & $28.0[25.5-30.5](25)$ & 0.899 \\
\hline \multicolumn{5}{|c|}{ Mean $[95 \% \mathrm{CI}] \mathrm{BMI}$ in each group (n) } \\
\hline- & Normal $(<25.0)$ & $22.7[21.8-23.7](13)$ & $22.2[20.5-23.9](9)$ & 0.486 \\
\hline- & Overweight $(25.0$ - 29.9) & $27.8[26.7-28.8](10)$ & $27.0[25.5-28.5](7)$ & 0.326 \\
\hline- & Obese $(\geq 30.0)$ & 35.1 [32.1 - 38.1] (9) & $34.6[31.8-37.3](9)$ & 0.769 \\
\hline
\end{tabular}


Overall the participants in the Glubran-2 arm showed a higher total volume of seroma. The mastectomy group in the Glubran-2 arm had a higher volume (1203 versus $766 \mathrm{mls}, P=0.288$ ) and longer duration for seroma resolution (55 versus 35.5 days, $P=0.07$ ) (Table 2 ).

In the Glubran-2 arm, participants over 70 years of age who underwent total mastectomy showed more than double the volume of seroma when compared to the saline arm (1692 versus $804 \mathrm{mls}, P=0.324$ ). Participants between the age of 50 - 60 who underwent total mastectomy and axillary dissection in the Glubran-2 arm showed a significantly higher volume of seroma (5820 versus 2438 mls, $P=0.171)$. Elderly participants over the age of 70 in the saline arm showed a higher volume (4,047 versus $2086 \mathrm{mls}, P=0.244)$. In the Glubran-2 arm and partial mastectomy group, participants between the ages of 60 - 70 had higher volume of seroma (973 versus $275 \mathrm{mls}, P=0.234$ ) (Table 3 ).

All obese (BMI > 30) participants in the Glubran-2 arm except partial mastectomy group showed a higher total volume of seroma. There was no statistical significant difference between the groups (Table 4).

Overall the post-operative wound infection rate was higher in the Glubran-2 arm (13.2\% versus 5.6\%, $P=0.262$ ) (Table 5).

Two participants who underwent total mastectomy in the Glubran-2 arm experienced persistently high volume bloodstained seroma for over two months, which required wound exploration and debridement. Intraoperative findings showed a cavity lined with bleeding hypergranulation tissue. The histology revealed intense foreign body reaction.

Table 2. Post-operative seroma outcomes.

\begin{tabular}{|c|c|c|c|}
\hline Characteristics & $\begin{array}{c}\text { Glubran-2 } \\
(\mathrm{n}=38)\end{array}$ & $\begin{array}{l}\text { Saline } \\
(n=36)\end{array}$ & $P$-value \\
\hline \multicolumn{4}{|l|}{ Inpatient Seroma Drainage-mls (mean) } \\
\hline - Total Mastectomy & 157 & 285 & 0.291 \\
\hline - $\quad$ Total Mastectomy and Axillary dissection & 383 & 380 & 0.971 \\
\hline - $\quad$ Partial Mastectomy and Axillary dissection & 227 & 205 & 0.806 \\
\hline \multicolumn{4}{|l|}{ Total Seroma Drainage-mls (mean) } \\
\hline - $\quad$ Total Mastectomy & 1203 & 766 & 0.288 \\
\hline - Total Mastectomy and Axillary dissection & 2916 & 2905 & 0.991 \\
\hline - Partial Mastectomy and Axillary dissection & 729 & 676 & 0.849 \\
\hline \multicolumn{4}{|l|}{ Duration of Seroma-days (median) } \\
\hline - $\quad$ Total Mastectomy & 55.0 & 35.5 & 0.070 \\
\hline - Total Mastectomy and Axillary dissection & 61.5 & 62.0 & 0.696 \\
\hline - Partial Mastectomy and Axillary dissection & 28.0 & 25.5 & 0.240 \\
\hline
\end{tabular}


Table 3. Post-operative seroma outcomes as per age.

\begin{tabular}{|c|c|c|c|}
\hline Characteristics & $\begin{array}{c}\text { Glubran-2 } \\
(\mathrm{n}=38)\end{array}$ & $\begin{array}{l}\text { Saline } \\
(n=36)\end{array}$ & $P$-value \\
\hline \multicolumn{4}{|l|}{ Inpatient Seroma Drainage-mls (mean) } \\
\hline Total Mastectomy (n) & $157(16)$ & $285(14)$ & 0.291 \\
\hline$-\quad<50$ years & $113(3)$ & $260(2)$ & 0.141 \\
\hline - $50-60$ years & $173(3)$ & - & - \\
\hline - $60-70$ years & $278(3)$ & $347(7)$ & 0.864 \\
\hline - $\quad>70$ years & $117(7)$ & $208(5)$ & 0.310 \\
\hline Total Mastectomy + Axillary Dissection (n) & $383(16)$ & $380(16)$ & 0.971 \\
\hline - $\quad<50$ years & $303(3)$ & $290(6)$ & 0.934 \\
\hline - $50-60$ years & $628(2)$ & $190(1)$ & 0.381 \\
\hline - $60-70$ years & $474(5)$ & $500(4)$ & 0.869 \\
\hline - $\quad>70$ years & $265(6)$ & $430(5)$ & 0.202 \\
\hline Partial Mastectomy + Axillary Dissection (n) & $227(6)$ & $205(6)$ & 0.806 \\
\hline$-\quad<50$ years & - & $135(2)$ & - \\
\hline - $50-60$ years & $197(3)$ & $404(2)$ & 0.144 \\
\hline - $60-70$ years & $257(3)$ & $130(1)$ & 0.569 \\
\hline - $\quad>70$ years & - & $20(1)$ & - \\
\hline \multicolumn{4}{|c|}{ Total Seroma Drainage-mls (mean) } \\
\hline Total Mastectomy (n) & $1203(16)$ & $766(14)$ & 0.288 \\
\hline$-\quad<50$ years & $727(3)$ & $285(2)$ & 0.437 \\
\hline - $50-60$ years & $1031(3)$ & - & - \\
\hline - $60-70$ years & $710(3)$ & $876(7)$ & 0.796 \\
\hline - $\quad>70$ years & $1692(7)$ & $804(5)$ & 0.324 \\
\hline Total Mastectomy + Axillary Dissection (n) & $2916(16)$ & $2905(16)$ & 0.991 \\
\hline - $\quad<50$ years & $807(3)$ & $2658(6)$ & 0.323 \\
\hline - $50-60$ years & $1313(2)$ & $540(1)$ & 0.439 \\
\hline - $60-70$ years & $5820(5)$ & $2438(4)$ & 0.171 \\
\hline - $\quad>70$ years & $2086(6)$ & $4047(5)$ & 0.244 \\
\hline Partial Mastectomy + Axillary Dissection (n) & $729(6)$ & $676(6)$ & 0.849 \\
\hline - $\quad<50$ years & - & $363(2)$ & - \\
\hline - $50-60$ years & $485(3)$ & $819(2)$ & 0.469 \\
\hline - $60-70$ years & $973(3)$ & $275(1)$ & 0.234 \\
\hline - $\quad>70$ years & - & $1415(1)$ & - \\
\hline
\end{tabular}


Table 4. Post-operative seroma outcomes as per BMI.

\begin{tabular}{|c|c|c|c|}
\hline Characteristics & $\begin{array}{c}\text { Glubran } 2 \\
(\mathrm{n}=38)\end{array}$ & $\begin{array}{l}\text { Saline } \\
(\mathrm{n}=36)\end{array}$ & $P$-value \\
\hline \multicolumn{4}{|c|}{ Inpatient Seroma Drainage-mls (mean) } \\
\hline \multicolumn{4}{|c|}{ Total Mastectomy (BMI) } \\
\hline - $\quad$ Normal $(<25.0)$ & $94(6)$ & $100(5)$ & 0.909 \\
\hline - $\quad$ Overweight $(25.0-29.9)$ & $230(4)$ & $657(3)$ & 0.430 \\
\hline - $\quad$ Obese $(\geq 30.0)$ & $172(6)$ & $260(4)$ & 0.311 \\
\hline \multicolumn{4}{|c|}{ Total Mastectomy + Axillary Dissection (BMI) } \\
\hline - $\quad$ Normal $(<25.0)$ & $277(8)$ & $302(6)$ & 0.837 \\
\hline - $\quad$ Overweight $(25.0$ - 29.9) & $540(4)$ & $470(3)$ & 0.725 \\
\hline - $\quad$ Obese $(\geq 30.0)$ & $438(4)$ & $392(6)$ & 0.749 \\
\hline \multicolumn{4}{|c|}{ Partial Mastectomy + Axillary Dissection (BMI) } \\
\hline - $\quad$ Normal $(<25.0)$ & $157(3)$ & $187(3)$ & 0.625 \\
\hline - $\quad$ Overweight $(25.0-29.9)$ & $297(3)$ & $70(2)$ & 0.112 \\
\hline - $\quad$ Obese $(\geq 30.0)$ & - & $528(1)$ & - \\
\hline \multicolumn{4}{|c|}{ Total Seroma Drainage-mls (mean) } \\
\hline \multicolumn{4}{|c|}{ Total Mastectomy (BMI) } \\
\hline - $\quad$ Normal $(<25.0)$ & $407(6)$ & $216(5)$ & 0.365 \\
\hline - $\quad$ Overweight $(25.0-29.9)$ & $1132(4)$ & $1400(3)$ & 0.736 \\
\hline - $\quad$ Obese $(\geq 30.0)$ & $2046(6)$ & $1016(3)$ & 0.304 \\
\hline \multicolumn{4}{|c|}{ Total Mastectomy + Axillary Dissection (BMI) } \\
\hline - $\quad$ Normal $(<25.0)$ & $1349(8)$ & $798(6)$ & 0.303 \\
\hline - $\quad$ Overweight $(25.0$ - 29.9) & $2942(4)$ & $4451(3)$ & 0.400 \\
\hline - $\quad$ Obese $(\geq 30.0)$ & $6024(4)$ & $3629(6)$ & 0.358 \\
\hline \multicolumn{4}{|c|}{ Partial Mastectomy + Axillary Dissection (BMI) } \\
\hline - $\quad$ Normal $(<25.0)$ & $563(3)$ & $387(3)$ & 0.243 \\
\hline - $\quad$ Overweight $(25.0-29.9)$ & $895(3)$ & $768(2)$ & 0.843 \\
\hline - $\quad$ Obese $(\geq 30.0)$ & - & $1358(1)$ & - \\
\hline
\end{tabular}

Table 5. Post-operative infection requiring antibiotics.

\begin{tabular}{cccc}
\hline Characteristics & $\begin{array}{c}\text { Glubran2 } \\
(\mathrm{n}=38)\end{array}$ & $\begin{array}{c}\text { Saline } \\
(\mathrm{n}=36)\end{array}$ & $P$-value \\
\hline Total $\left(\mathrm{n}_{\mathbf{1}} / \mathrm{n}\right)(\%)$ & $5 / 38(13.2 \%)$ & $2 / 36(5.6 \%)$ & 0.262 \\
-Total Mastectomy $\left(\mathrm{n}_{\mathbf{1}} / \mathrm{n}\right)(\%)$ & $2 / 16(12.5 \%)$ & $0 / 14(0 \%)$ & 0.170 \\
-Total Mastectomy + Axillary Dissection & $2 / 16(12.5 \%)$ & $1 / 16(6.2 \%)$ & 0.541 \\
$\left(\mathrm{n}_{\mathbf{1}} / \mathrm{n}\right)(\%)$ & & & \\
-Partial Mastectomy + Axillary Dissection $\left(\mathrm{n}_{1} / \mathrm{n}\right)(\%)$ & $1 / 6(16.7 \%)$ & $1 / 6(16.7 \%)$ & 1.0 \\
\hline
\end{tabular}

\section{Discussion}

Seroma formation and its complications can have a significant impact on the patients overall recovery [1] [3] [5] [6] [7]. Seroma can lead to prolonged hospital 
stay, increased frequency of clinic visits for aspirations, increased risks of wound infection and delayed wound healing. This can increase the patients overall morbidity and delay their adjuvant treatment. This can lead to unnecessary additional financial burden to the healthcare system [1] [3] [7] [14] [15] [16] [17] [18].

Several techniques such as suturing the flaps, prolonged use of drains, and pressure dressing have not shown any benefit in reducing seroma formation [2] [3] [6]-[11]. Pharmaceutical agents such as fibrin glue, light activated fibrin sealant, tetracycline, somatostatin analogues, corticosteroids, and sclerosing agents have been trialled but failed to demonstrate any convincing benefit in reducing seroma formation [2] [6]-[15]. Quilting sutures have been shown to have some benefit in reducing seroma formation, volume and length of drainage time but can cause significant pain and discomfort [16] [17] [18]. Despite all these techniques and agents there is no efficient single solution to tackle this common complication.

To the best of our knowledge there are no previous randomised trials published in mastectomy or axillary surgery investigating the efficacy of Glubran-2 in seroma formation. Although the use of Glubran-2 as an adjunct in other areas such as pelvic lymphadenectomy showed reduced lymph production, there was no such benefit shown in our study [24]. The findings of this study were that the use of Glubran-2 did not reduce the risk, volume or duration of seroma. In fact the use of Glubran-2 can increase the volume of seroma, particularly in elderly and overweight participants. Participants in the Glubran-2 arm also showed increased rate of post-operative wound infection. However there was no statistically significant difference between the Glubran-2 and saline group. Therefore it is difficult to draw a definitive conclusion.

In 2017, the estimated incidence of breast cancer diagnosis in Australia is approximately 17,000 [25]. Approximately $30 \%$ - 40\% of those diagnosed are treated with a mastectomy [26]. Each vial of Glubran-2 cost approximately AUD \$300.00. Participants undergoing mastectomy alone require one vial and mastectomy and axillary dissection require 2 vials of Glubran-2. This can lead to significant additional cost to our healthcare system. As our study did not find any positive benefit in reducing seroma formation, use of Glubran-2 in mastectomy and axillary surgery may not be beneficial. In fact its use may increase the overall cost of the surgery without any potential benefit to the patient outcome.

\section{Conclusion}

In conclusion, this double-blinded randomised controlled trial did not show any benefit with the use of Glubran-2 in mastectomy and axillary surgery in reducing the risk of seroma formation. In some patient groups the use of Glubran-2 showed increase in seroma formation. But there was no statistically significant difference to generalise the findings of this study. Being a pilot study the main limitation is the sample size. Therefore the findings are underpowered. However, this study can work as a platform for future research using a larger sample 
size to further assess the impact of Glubran-2 on seroma formation after mastectomy and axillary surgery.

\section{Acknowledgements}

We acknowledge Matrix Surgical Australia for providing the Glubran-2 and Saline spray for this study. We also acknowledge our breast care nurses Janet Rice, Merralyn Briskham, and Rachel Buder for their assistance.

\section{Conflict of Interest}

The authors declare that they have no conflict of interest.

\section{References}

[1] Kumar, S., Lal, B. and Misra, M.C. (1995) Post-Mastectomy Seroma: A New Look into the Aetiology of an Age-Old Problem. Journal of the Royal College of Surgeons of Edinburgh, 40, 27-29.

[2] Sampathraju, S. and Rodrigues, G. (2010) Seroma Formation after Mastectomy: Pathogenesis and Prevention. Indian Journal of Surgical Oncology, 1, 328-333. https://doi.org/10.1007/s13193-011-0067-5

[3] Srivastava, V., Basu, S. and Shukla, V.K. (2012) Seroma Formation after Breast Cancer Surgery: What We Have Learned in the Last Two Decades. Journal of Breast Cancer, 15, 373-380. https://doi.org/10.4048/jbc.2012.15.4.373

[4] Park, S.Y., Kim, E.Y., Park, H.K., et al. (2014) Computed Tomographic Findings of Postoperative Seroma in Breast Cancer Patients. Journal of Breast Disease, 2, 64-68. https://doi.org/10.14449/jbd.2014.2.64

[5] Faisal, M., Abu-Elela, S.T., Mostafa, W., et al. (2016) Efficacy of Axillary Clearance on Seroma Formation after Modified Radical Mastectomy. World Journal of Surgical Oncology, 14, 1-5. https://doi.org/10.1186/s12957-016-0801-0

[6] Turner, E.J., Benson, J.R. and Winters, Z.E. (2014) Techniques in the Prevention and Management of Seromas after Breast Surgery. Future Oncology, 10, 1049-1063. https://doi.org/10.2217/fon.13.257

[7] Concersano, A., Mazouni, C., Thomin, A., et al. (2017) Use of Low-Thrombin Fibrin Sealant Glue after Axillary ly Phadenectomy for Breast Cancer to Reduce Hospital Length and Seroma. Clinical Breast Cancer, 17, 293-297. https://doi.org/10.1016/j.clbc.2016.12.013

[8] Kuroi, K., Shimozuma, K., Taguchi, T., et al. (2006) Evidence-Based Risk Factors for Seroma Formation in Breast Surgery. Japanese Journal of Clinical Oncology, 36, 197-206. https://doi.org/10.1093/jjco/hyl019

[9] Coveney, C.Y., O’Dwyer, P.J., Geraghty, J.G., et al. (1993) Effect of Closing Dead Space on Seroma Formation after Mastectomy-A Prospective Randomised Clinical Trial. European Journal of Surgical Oncology, 19, 143-146.

[10] Kuroi, K., Shimozuma, K., Taguchi, T., et al. (2006) Effect of Mechanical Closure of Dead Space on Seroma Formation after Breast Surgery. Breast Cancer, 13, 260-265. https://doi.org/10.2325/jbcs.13.260

[11] Janis, J.E., Khansa, L. and Khansa, I. (2016) Strategies for Postoperative Seroma Prevention: A Systematic Review. Plastic and Reconstructive Surgery, 138, 240-252. https://doi.org/10.1097/PRS.0000000000002245 
[12] Bonjar, M.R.M., Maghsoudi, H., Samnia, R., et al. (2012) Efficacy of Fibrin Glue on Seroma Formation after Breast Surgery. International Journal of Breast Cancer, 2012, Article ID: 643132.

[13] Jain, P.K., Sowdi, R., Anderson, A.D.G., et al. (2004) Randomized Clinical Trial Investigating the Use of Drains and Fibrin Sealant Following Surgery for Breast Cancer. British Journal of Surgery, 91, 54-60. https://doi.org/10.1002/bjs.4435

[14] Qvamme, G., Axelsson, C.K., Lanng, C., et al. (2015) Randomised Clinical Trial of Prevention of Seroma Formation after Mastectomy by Local Methylprednisolone Injection. British Journal of Surgery, 102, 1195-1203. https://doi.org/10.1002/bjs.9874

[15] Rice, D.C., Morris, S.M., Sarr, M.G., et al. (2000) Intraoperative Tropical Tetracycline Sclerotherapy Following Mastectomy: A Prospective Randomised Trial. Jour nal of Surgical Oncology, 73, 224-227. https://doi.org/10.1002/(SICI)1096-9098(200004)73:4<224::AID-JSO7>3.0.CO;2-0

[16] Mazouni, C., Mesnard, C., Clouter, A., et al. (2015) Quilting Sutures Reduces Seroma in Mastectomy. Clinical Breast Cancer, 15, 289-293.

[17] Van Bastellar, J., Beckers, A., Snoejis, M., et al. (2016) Flap Fixation Reduces Seroma in Patients Undergoing Mastectomy: A Significant Implication for Clinical Practice. World Journal of Surgical Oncology, 14, 66. https://doi.org/10.1186/s12957-016-0830-8

[18] Ouldamer, L., Bonastre, J., Brunet-Houdard, S., et al. (2016) Dead Space Closure with Quilting Suture versus Conventional Closure with Drainage for the Prevention of Seroma after Mastectomy for Breast Cancer (QUISERMAS): Protocol for Multicentre Randomised Controlled Trial. BMJ Open, 6.

[19] Kull, S., Eng, M., Martinelli, I., et al. (2009) Glubran 2 Surgical Glue: In Vitro Evaluation of Adhesive and Mechanical Properties. Journal of Surgical Research, 157, e15-e21.

[20] Haghpanah, S., Vafar, A., Golzadeh, M.H., et al. (2011) Use of Glubran 2 and Glubran Tissue Skin Adhesive in Patients with Hereditary Bleeding Disorders Undergoing Circumcision and Dental Extraction. Annals of Hematology, 90, 463-468. https://doi.org/10.1007/s00277-010-1086-y

[21] Paajanen, H., Kossi, J., Silvasti, S., et al. (2011) Randomised Clinical Trial of Tissue Glue versus Absorbable Sutures for Mesh Fixation in Local Anaesthetic Lichtenstein Hernia Repair. British Journal of Surgery, 98, 1245-1251. https://doi.org/10.1002/bjs.7598

[22] Lasheen, A.E., Tolba, A.M., Mohamed, H., et al. (2013) Laparoscopic Inguinal Hernia Repair with Closure of Hernia Defect and Central Mesh Fixation using Glubran 2. Surgical Science, 4, 554-557. https://doi.org/10.4236/ss.2013.412107

[23] Garcia-Vallejo, L., Couto-Gonzalez, I., Concheiro-Coello, P., et al. (2014) Cyanoacrylate Surgical Glue for Mesh Fixation in Laparoscopic Total Extraperitoneal Hernia Repair. Surgical Laparoscopy Endoscopy \& Percutaneous Techniques, 24, 240-243. https://doi.org/10.1097/SLE.0b013e3182a2f008

[24] Bifulco, G., Giampaolino, P., Morra, I., et al. (2014) Synthetic Cyanoacrylic Glue in the Prevention of Post-Operative Lymphocele after Pelvic Lymphadenectomy in $\mathrm{Pa}$ tients with Uterine Malignancies: A Prospective, Single Blinded, Preliminary Study. Gynecologic Oncology, 134, 556-560.

[25] AIHW (2017) Cancer in Australia 2017 [PDF on Internet]. Cancer Series No. 101, Cat. No. CAN 100, Australian Government, Canberra. http://www.aihw.gov.au/WorkArea/DownloadAsset.aspx?id=60129559144 
[26] Roder, D., Zorbas, H., Kollias, J., et al. (2013) Factors Predictive of Treatment by Australian Breast Surgeons of Invasive Female Breast Cancer by Mastectomy Rather than Breast Conserving Surgery. Asian Pacific Journal of Cancer Prevention, 14, 539-545. https://doi.org/10.7314/APJCP.2013.14.1.539 